\title{
Abiotic stresses induce total phenolic, total flavonoid and antioxidant properties in Malaysian indigenous microalgae and cyanobacterium
}

\author{
Nur Husna Azim ${ }^{1}$, Atiqah Subki ${ }^{1}$, Zetty Norhana Balia Yusof ${ }^{1,2 *}$ \\ ${ }^{1}$ Department of Biochemistry, Faculty of Biotechnology and Biomolecular Sciences, Universiti Putra Malaysia, 43400 \\ UPM, Serdang, Selangor, Malaysia \\ ${ }^{2}$ Laboratory of Marine Biotechnology, Institute of Bioscience, Universiti Putra Malaysia, 43400 UPM, Serdang, Selangor, \\ Malaysia \\ Email: zettynorhana@upm.edu.my
}

Received 2 February 2017; Received in revised form 14 June 2017; Accepted 20 June 2017

\begin{abstract}
Aims: The use of microalgae as source of natural antioxidants is under explored in Malaysia. Previous studies have shown that microalgae contain minerals, polysaccharides, amino derivatives, carotenoids and phenolic compounds. This study aimed to determine total phenolic and flavonoid compounds and antioxidant activity when microalgae (Nannochloropsis oculata and Tetraselmis sp.) and cyanobacterium (Anabaena sp.) were subjected to abiotic stresses. Methodology and results: Treatment of sodium chloride $(\mathrm{NaCl})$, sodium hypochlorite $(\mathrm{NaOCl})$ and $\operatorname{copper}\left(\mathrm{Cu}^{2+}\right)$ were given when the cultures reached the exponential phase of growth and were collected at three different time points. Nontreated cultures were used as controls. Total phenolic and flavonoid contents were determined using Folin-Ciocalteau phenol reagent and aluminium chloride colorimetric assays. Antioxidant activities were measured using 2,2-diphenyl-1picrylhydrazyl (DPPH) free radical scavenging activity assay. Tetraselmis sp. exhibited the highest phenolic content under copper stress (10.35 $\pm 0.33 \mu \mathrm{g} \mathrm{GAE} / \mathrm{mg}$ extract). Nannochloropsis oculata showed the highest total flavonoid content under copper stress $(33.85 \pm 3.16 \mu \mathrm{g} \mathrm{QE} / \mathrm{mg}$ extract). Anabaena sp. showed the highest radical scavenging activity under $\mathrm{NaOCI}$ stress $(96.42 \pm 0.26 \%)$.

Conclusion, significance and impact of study: This study showed that total phenolic, flavonoid and antioxidant activities in treated cultures were high compared to non-treated cultures. These microorganisms could be utilized as a source of useful bioactive compounds while exploiting its abundance.
\end{abstract}

Keywords: microalgae, cyanobacteria, antioxidant, stress

\section{INTRODUCTION}

Antioxidants are molecules that inhibit free radicals that are produced from the oxidation of other molecules. Most foods and pharmaceutical industries use synthetic antioxidants to prolong product shelf life and to enhance the stability of therapeutic agents. Synthetic antioxidants are widely used as it is cheaper than natural antioxidants. The two most common synthetic antioxidants used today are butylated hydroxyanisole (BHA) and butylated hydroxytoluene (BHT). However, recent studies have shown that these synthetic antioxidants are suspected to be carcinogenic (Maadane et al., 2015) and will consequently result in DNA damage (Abd El-Aty et al., 2014).

Primary source for natural antioxidants are plants, but the production of antioxidants from plants are costly and time consuming. Recently, interests in the utilization of microalgae have increased due to their high secondary metabolites activities and also because they have been recognized as a new source of antioxidants apart from plants (Maadane et al., 2015). Microalgae are photosynthetic unicellular microorganism that can be cultivated in a large-scale system at fast pace. Recent study by Klejdus et al. (2010) showed that several classes of flavonoids can be found in microalgae and cyanobacteria and they showed capabilities in inhibiting lipid peroxidation. Studies by Klejdus et al. (2010) and Kováčik et al. (2010) showed that a variety of phenolic compounds are present in microalgae. Natrah et al. (2007) also revealed that some microalgae such as Isochrysis galbana and Chaetoceros calcitrans have the potential to be utilized as natural sources of antioxidants with high nutritional value.

Interestingly, the adaptability towards stress in algae was found to be associated with accumulation of several organic solutes which includes phenolic, flavonoid and antioxidant compounds (Hasegawa et al., 2000). This may 
be due to the increase in production of reactive oxygen species (ROS) radical molecules under stress conditions which leads to oxidative damage (Kreslavski et al., 2007). The growing interest in the search of natural antioxidants to replace the synthetics is currently ongoing. Nevertheless, the exploration of antioxidant compounds from microalgae is lacking in Malaysia. This project was carried out in order to determine the amount of phenolic and flavonoid compounds in microalgae ( $N$. oculata and Tetraselmis sp.) and cyanobacterium (Anabaena sp.) and the effects of abiotic stresses towards the antioxidant activities in these organisms.

\section{MATERIALS AND METHODS}

\section{Microalgae samples}

Cyanobacterium Anabaena sp. was kindly given by $\mathrm{Dr}$. Japareng Lalung from Universiti Sains Malaysia (USM), Penang while microalgae ( $N$. oculata and Tetraselmis sp.) were obtained from Centre of Marine Science (COMAS), Universiti Putra Malaysia (UPM), Port Dickson. Anabaena sp. was grown in $250 \mathrm{~mL}$ Erlenmeyer flask that was placed on an open orbital shaker at $29 \pm 2{ }^{\circ} \mathrm{C}$ and continuously shaken at $150 \mathrm{rpm}$ for $24 \mathrm{~h}$ under $50 \mu \mathrm{mol}$ photons $\mathrm{m}^{-2} \mathrm{~s}^{-1}$ illumination. The medium used was modified BG-11 at $\mathrm{pH} 7.2$.

N. oculata and Tetraselmis sp. were grown in $1000 \mathrm{~mL}$ Erlenmeyer flask at $26 \pm 2{ }^{\circ} \mathrm{C}$ in an incubator shaker at Agro-Biotechnology Institute $(\mathrm{ABI})$, Selangor. Both species were grown under $50 \mu \mathrm{mol}$ photons $\mathrm{m}^{-2} \mathrm{~s}^{-1}$ illumination for $24 \mathrm{~h}$ and continuously shaken at $150 \mathrm{rpm}$. The medium used was TAP/2 seawater at $\mathrm{pH} 7.1$.

\section{Treatment application}

Treatments were applied when the growth of the organisms reached exponential phase (OD1000 $\mathrm{nm}=0.8$ ). The experiments were carried out by supplementing the media with increasing concentrations of stress inducers namely, copper $\left[\left(\mathrm{Cu}^{2+}\right)(0.5,2\right.$ and $\left.5 \mathrm{ppm})\right]$, sodium hypochlorite $[(\mathrm{NaOCl})(0.5,10$ and $5 \mu \mathrm{M})]$ and sodium chloride [( $\mathrm{NaCl})(50,150$ and $250 \mathrm{mM})]$. Samples were collected at day $0\left(D_{0}\right)$, day $3\left(D_{3}\right)$ and day $6\left(D_{6}\right)$ to see the effects immediately after the application and the next few days up to day 6 which were predicted to be the points where the full effects have taken in.

\section{Preparation of sample extracts}

Crude extraction was carried out using HPLC grade methanol (Merck, Germany) as an extraction solvent. A volume of $200 \mathrm{~mL}$ of each culture was centrifuged at 8000 $x g$ for $30 \mathrm{~min}$ at $15^{\circ} \mathrm{C}$. The supernatant was discarded while the pellet was retrieved and dried at $60^{\circ} \mathrm{C}$ for $2 \mathrm{~h}$. The dried pellet was weighed and mixed with methanol $(1: 40, w / v)$. Extractions were performed overnight with continuous stirring. The supernatant was recovered after centrifugation of the mixture at $8000 \times g$ for $30 \mathrm{~min}$ at 15 ${ }^{\circ} \mathrm{C}$ by filtering the supernatant through Whatman filter paper. The supernatant was dried using rotary evaporator. The dried extracts were resuspended with $1 \mathrm{~mL}$ methanol to a specific final concentration and stored at $-20^{\circ} \mathrm{C}$ until further use (Guedes et al., 2011).

\section{Total phenolic content assays}

Total phenolic content was determined using spectrophotometric method by Slinkard and Singleton (1977). The extracts were prepared with a concentration of $100 \mu \mathrm{g} / \mathrm{mL}$. A volume of $0.5 \mathrm{~mL}$ of each extract was added with distilled water to up to $3 \mathrm{~mL}$ and $0.5 \mathrm{~mL}$ of Folin-Ciocalteau's phenol reagent. After $5 \mathrm{~min}, 2 \mathrm{~mL}$ of 2 $\%$ sodium carbonate $\left(\mathrm{Na}_{2} \mathrm{CO}_{3}\right)$ solution was added and left for $60 \mathrm{~min}$ in the dark before the absorbance was taken. The calibration curve was extrapolated to determine the total phenolic content using gallic acid solution $(10-70 \mu \mathrm{M})$ and the results were expressed in gallic acid equivalents per $\mathrm{mg}$ of extracts, GAE/mg.

\section{Total flavonoid content assays}

Total flavonoid content was determined by a calorimetric method (Zishen et al., 1999). Approximately $0.5 \mathrm{~mL}$ of each extract with the concentration of $100 \mu \mathrm{g} / \mathrm{mL}$ was added with $1 \mathrm{~mL} 100 \%$ methanol to make up to $3 \mathrm{~mL}$. The mixture was left for 5 min after the addition of $0.4 \mathrm{~mL}$ distilled water and $0.3 \mathrm{~mL}$ of $5 \%$ sodium nitrite $\left(\mathrm{NaNO}_{2}\right)$. Approximately $2 \mathrm{~mL}$ of $1 \mathrm{M}$ sodium hydroxide $(\mathrm{NaOH})$ and distilled water was added to make up to $10 \mathrm{~mL}$ after 0.3 $\mathrm{mL}$ of $10 \%$ aluminium chloride $\left(\mathrm{AlCl}_{3}\right)$ was added and left at room temperature for $1 \mathrm{~min}$. The mixture was left for 15 min after being shaken. The absorbance was measured at $510 \mathrm{~nm}$ and the concentrations of total flavonoids were determined as quercetin equivalents per $\mathrm{mg}$ of extracts, $\mathrm{QE} / \mathrm{mg}$.

\section{Antioxidant assay}

The antioxidant activity (AA \%) of samples were assessed by DPPH free radical assay according to method described by Blois (1958). The samples were prepared with a concentration of $100 \mu \mathrm{g} / \mathrm{mL}$. The reaction mixture consisted of $3 \mathrm{~mL}$ of sample and $1 \mathrm{~mL}$ of DPPH radical solution. The changes in colour (from deep violet to light yellow) were measured at $517 \mathrm{~nm}$ after $60 \mathrm{~min}$ of reaction. The capacity of the 2,2-diphenyl-1-picrylhydrazyl (DPPH) radical scavenging activity was calculated using following formula:

$$
D P P H \text { scavenging effect }(\%)=\frac{(A D P P H-A S)}{A D P P H} \times 100
$$

ADPPH is the absorbance of the DPPH solution without any addition of extracts while, AS is the absorbance of the DPPH solution when the sample extract was added. 


\section{Statistical analysis}

Collected data were analysed using analysis of variance or t-test procedure. Significant differences between treatments were tested using Duncan's multiple range test (DMRT). Statistical analyses were carried out using Statistical Package for the Social Sciences (SPSS) 10.0.

\section{RESULTS}

The effect of $\mathrm{NaCl}, \mathrm{NaOCl}$ and $\mathrm{Cu}^{2+}$ on the growth of N. oculata, Tetraselmis sp. and Anabaena sp.

Effects of abiotic stresses $\left(\mathrm{NaCl}, \mathrm{NaOCl}\right.$ and $\left.\mathrm{Cu}^{2+}\right)$ on the growth of $N$. oculata, Tetraselmis sp. and Anabaena sp. are shown in Figure 1. Growth of $N$. oculata and Anabaena sp. after $\mathrm{NaCl}$ treatment increased (Figure 1A) with time but not more than control and high at $250 \mathrm{mM}$ $\left(\mathrm{OD}_{1000 \mathrm{~nm}}=0.951\right)$ and $150 \mathrm{mM}\left(\mathrm{OD}_{1000 \mathrm{~nm}}=0.701\right)$ respectively. Growth of treated Tetraselmis sp. was decreased while control was increased with time. Higher concentration of the treatment inhibited the growth of most of the cultures at $D_{6}\left(O D_{1000 \mathrm{~nm}}=0.8309\right)$.

As for $\mathrm{NaOCl}$ treatment (Figure 1B), growth of $N$. oculata and Anabaena sp. after treatment were increased with time but not more than control and high at $10 \mu \mathrm{M}$ $\left(O D_{1000 \mathrm{~nm}}=1.224\right)$ and $50 \mu \mathrm{M} \quad\left(\mathrm{OD}_{1000 \mathrm{~nm}}=0.701\right)$ respectively. Growth of treated Tetraselmis sp. was decreased while control was increased with time and inhibited the most at $10 \mu \mathrm{M}\left(O D_{1000 \mathrm{~nm}}=0.8309\right)$ respectively.

Figure $1 \mathrm{C}$ shows the growth of $N$. oculata and Anabaena sp. after treatment was increased over time but not more than control and high at $5 \mathrm{ppm}\left(\mathrm{OD}_{1000 \mathrm{~nm}=}\right.$ $1.287,0.701)$ respectively. Growth of treated Tetraselmis $\mathrm{sp}$. was decreased while control $\left(\mathrm{OD}_{1000 \mathrm{~nm}}=0.853\right)$ was increased with time and inhibited the most at $2 \mathrm{ppm}$ $\left(O D_{1000 \mathrm{~nm}}=1.015\right)$ respectively.

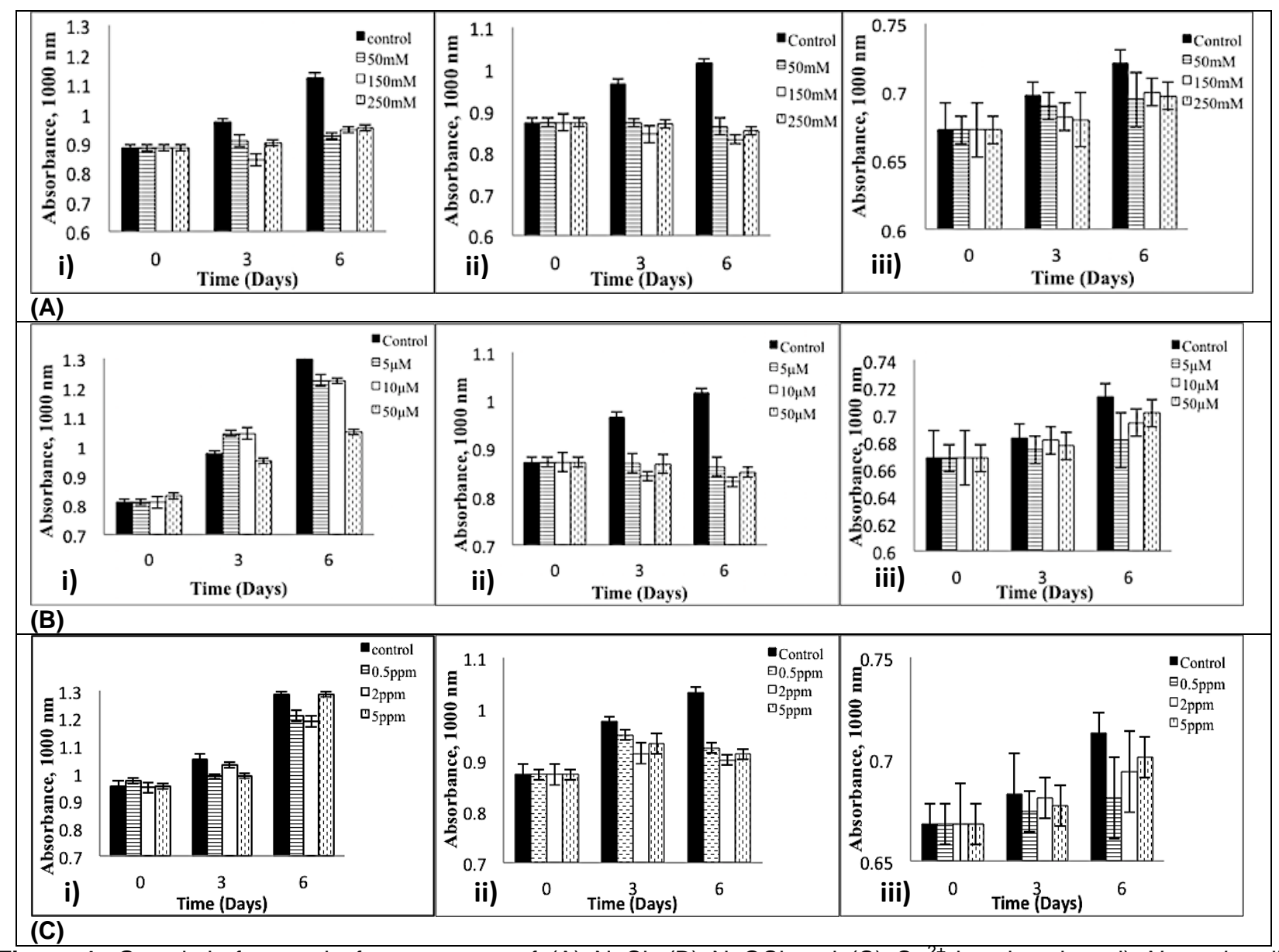

Figure 1: Growth before and after treatment of $(\mathrm{A}) \mathrm{NaCl},(\mathrm{B}) \mathrm{NaOCl}$ and (C) $\mathrm{Cu}^{2+}$ in microalgae i) $N$. oculata ii) Tetraselmis sp. iii) Anabaena sp. at different time points. The growth was monitored by measuring optical density at $1000 \mathrm{~nm}$. Each value in the graph is represented as mean \pm SD $(n=3)$. 
The effect of $\mathrm{NaCl}, \mathrm{NaOCl}$ And $\mathrm{Cu}^{2+}$ on the total phenolic content of $N$. oculata, Tetraselmis sp. and Anabaena sp.

The results of the effect of abiotic stresses $(\mathrm{NaCl}, \mathrm{NaOCl}$ and $\mathrm{Cu}^{2+}$ ) on total phenolic content in N. oculata, Tetraselmis sp. and Anabaena sp. are shown in Figure 2. In $\mathrm{NaCl}$ treatment (Figure $2 \mathrm{~A}$ ), the total phenolic content in all treated cultures were increased compared to nontreated cultures at all time points and all species exhibited the highest phenolic content at $D_{6}$. The highest amount of phenolic compounds in treated $N$. oculata was at $50 \mathrm{mM}$ (8.64 $\pm 0.6 \mu \mathrm{g} \mathrm{GAE} / \mathrm{mg}$ extract) as shown in Figure $2 \mathrm{~A}$ (i). The highest amount of phenolic compounds in treated Tetraselmis sp. and Anabaena sp. were at $250 \mathrm{mM}(7.02$ $\pm 0.33,2.77 \pm 0.55 \mu \mathrm{g} \mathrm{GAE} / \mathrm{mg}$ extract).

Total phenolic content in all treated cultures were also increased compared to non-treated cultures for $\mathrm{NaOCl}$ treatment (Figure 2B) and exhibited the highest phenolic content at $D_{6}$ for all species. The highest amount of phenolic compounds in $\mathrm{NaOCl}$ treated $N$. oculata was at $10 \mu \mathrm{M}(5.09 \pm 0.68 \mu \mathrm{g} \mathrm{GAE} / \mathrm{mg}$ extract). The highest amount of phenolic compounds in treated Tetraselmis sp. and Anabaena sp. were at $5 \mu \mathrm{M}$ of $\mathrm{NaOCl}(6.24 \pm 0.39$, $3.74 \pm 0.55 \mu \mathrm{g} \mathrm{GAE} / \mathrm{mg}$ extract).

Finally, for the $\mathrm{Cu}^{2+}$ treatment (Figure 2C), total phenolic content in all treated cultures were increased compared to non-treated cultures at each time point and exhibited the highest phenolic content at $5 \mathrm{ppm}$ of $\mathrm{Cu}^{2+}$. The highest amount of phenolic content in $\mathrm{Cu}^{2+}$ treated $\mathrm{N}$. oculata and Tetraselmis sp. was at $\mathrm{D}_{6}(5.51 \pm 0.68,10.35$ $\pm 0.33 \mu \mathrm{g} \mathrm{GAE} / \mathrm{mg}$ extract) while the highest phenolic content in $\mathrm{Cu}^{2+}$ treated Anabaena sp. was at day 3 (5.98 \pm 0.33, $\mu \mathrm{g} \mathrm{GAE} / \mathrm{mg}$ extract). All in all, among the three species, the highest amount of phenolic compounds was seen to be produced by Tetraselmis sp. when induced with 5 ppm Cu${ }^{2+}$ [Figure $2 \mathrm{C}$ (ii)].
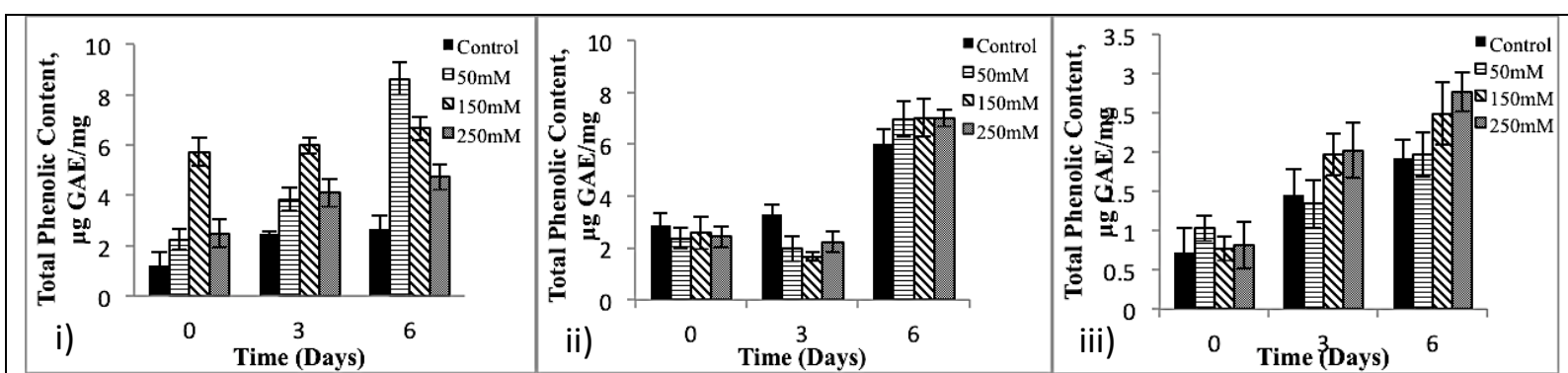

(A)
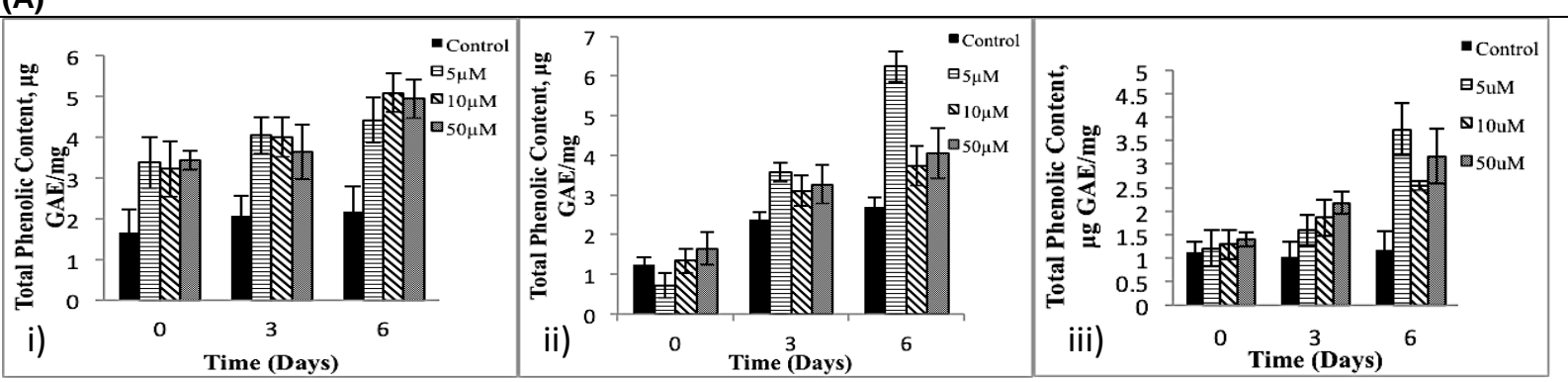

(B)
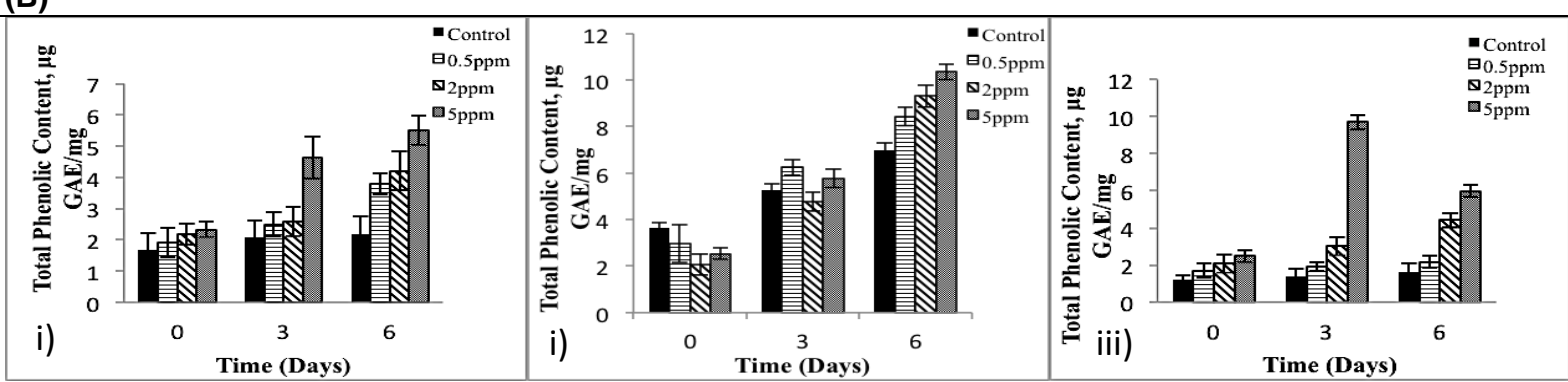

(C)

Figure 2: Total phenolic content before and after treatment of $(\mathrm{A}) \mathrm{NaCl}$, (B) $\mathrm{NaOCl}$ and (C) $\mathrm{Cu}^{2+}$ in i) $\mathrm{N}$. oculata ii) Tetraselmis sp. iii) Anabaena sp. at different time points. All treated and non-treated cultures initial concentration for the assay was $100 \mu \mathrm{g} / \mathrm{mL}$. Each value in the graph is represented as mean $\pm \operatorname{SD}(n=3)$. 
The effect of $\mathrm{NaCl}, \mathrm{NaOCl}$ and $\mathrm{Cu}^{2+}$ on the total flavonoid content of $\mathbf{N}$. oculata, Tetraselmis sp. and Anabaena sp.

The results of the effect of abiotic stresses $(\mathrm{NaCl}, \mathrm{NaOCl}$ and $\mathrm{Cu}^{2+}$ ) on total flavonoid content of $N$. oculata, Tetraselmis sp. and Anabaena sp. are shown in Figure 3. Total flavonoid content in all $\mathrm{NaCl}$ treated cultures were increased compared to non-treated cultures at each time point and exhibited the highest amount of flavonoid compounds at $D_{6}$ for all species (Figure $3 A$ ). The highest amount of flavonoid compounds in $\mathrm{NaCl}$ treated $N$

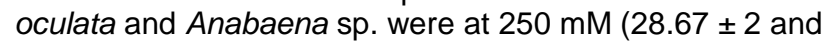
$21.63 \pm 3.89 \mu \mathrm{g} \mathrm{QE} / \mathrm{mg}$ extract). The highest amount of flavonoid compounds in treated Tetraselmis sp. was observed at $150 \mathrm{mM} \mathrm{NaCl}(22.17 \pm 3.70 \mu \mathrm{g} \mathrm{QE} / \mathrm{mg}$ extract).

In $\mathrm{NaOCl}$ treatment (Figure 3B), the highest amount of flavonoid compounds in N. oculata and Anabaena sp. were at $50 \mu \mathrm{M}(31.54 \pm 0.56,18.85 \pm 2.63 \mu \mathrm{g} \mathrm{QE} / \mathrm{mg}$ extract). On the other hand, the highest flavonoid content accumulated in treated Tetraselmis sp. was at $5 \mu \mathrm{M}$ $\mathrm{NaOCl}(23.29 \pm 2.63 \mu \mathrm{g} \mathrm{QE} / \mathrm{mg}$ extract) (Figure 3B (ii)).

Based on Figure $3 \mathrm{C}$, the total flavonoid content in all $\mathrm{Cu}^{2+}$ treated cultures were increased compared to nontreated cultures at each time point and exhibited the highest flavonoid content at $D_{6}$ for all species. The highest flavonoid content observed in treated $N$. oculata was at 5 ppm Cu${ }^{2+}(33.85 \pm 3.16 \mu \mathrm{g} Q \mathrm{QE} / \mathrm{mg}$ extract) while Tetraselmis sp. and Anabaena sp. were at $2 \mathrm{ppm} \mathrm{Cu}^{2+}$ $(28.67 \pm 3.59,20.33 \pm 3.09 \mu \mathrm{g} \mathrm{QE} / \mathrm{mg}$ extract $)$.

$N$. oculata was seen to produce the most number of flavonoid compounds when induced with all three types of stresses and the highest flavonoid content was induced by $\mathrm{Cu}^{2+}$ [Figure 3C (i)].
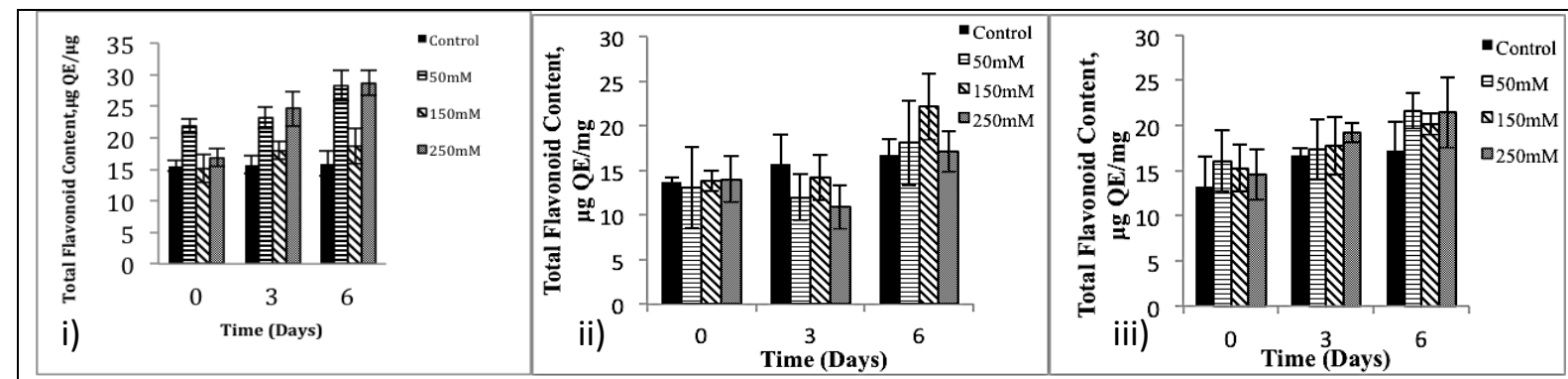

(A)
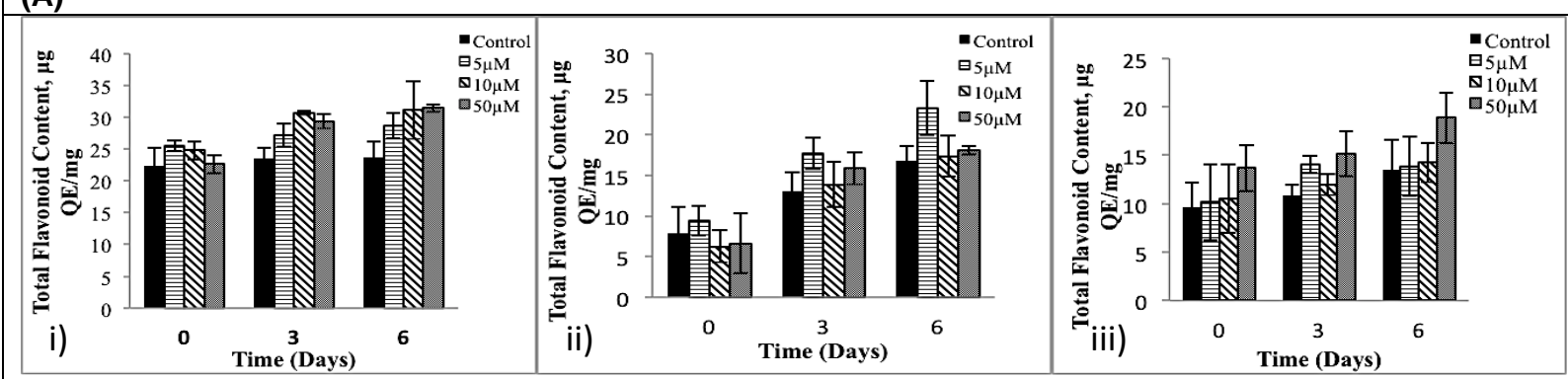

(B)
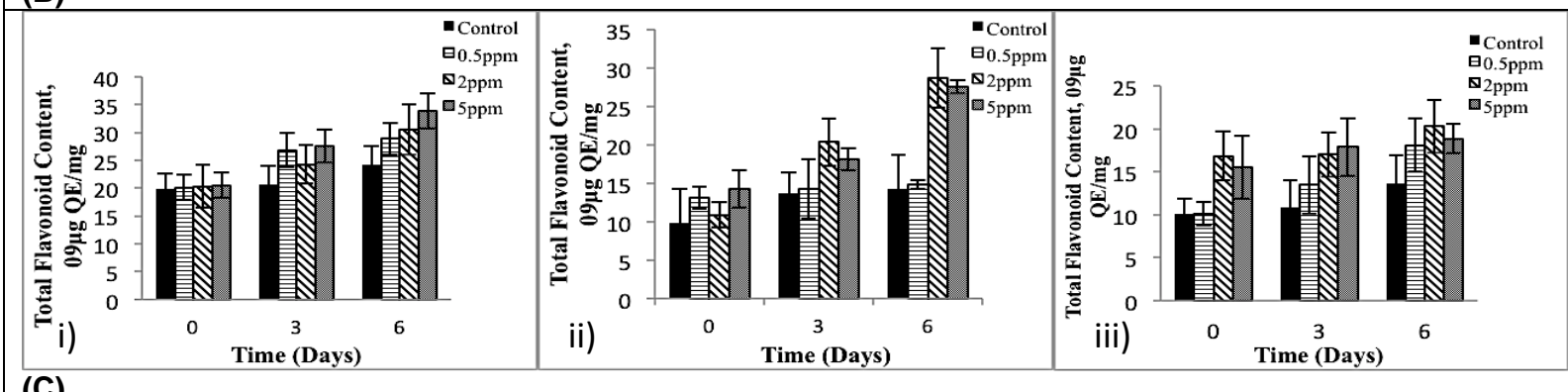

Figure 3: Total flavonoid content before and after treatment of (A) $\mathrm{NaCl}$, (B) $\mathrm{NaOCl}$ and (C) $\mathrm{Cu}^{2+}$ in i) $\mathrm{N}$. oculata ii) Tetraselmis sp. iii) Anabaena sp. at different time points. All samples and control concentrations were $100 \mu \mathrm{g} / \mathrm{mL}$. Each value in the graph is represented as mean $\pm S D(n=3)$. 
The effect of $\mathrm{NaCl}, \mathrm{NaOCl}$ and $\mathrm{Cu}^{2+}$ on the scavenging activity of $N$. oculata, Tetraselmis sp. and Anabaena sp.

The radical scavenging activities in all $\mathrm{NaCl}$ treated cultures were increased compared to non-treated cultures at each time point and the most activity was at $D_{6}$ for all species as shown in Figure 4A. The highest antioxidant activity in treated $N$. oculata, Tetraselmis sp. and Anabaena sp. were $87.95 \pm 0.62,85.96 \pm 0.46,93.07 \pm$ $0.42 \%$ inhibition of DPPH radical at $250 \mathrm{mM}$ respectively.

Radical scavenging activities in all $\mathrm{NaOCl}$ treated cultures (Figure 4B) were also increased compared to non-treated cultures at each time point and the most activity was at $D_{6}$ for all species. The highest antioxidant activity in treated $N$. oculata and Tetraselmis sp. with $90.41 \pm 0.44,91.10 \pm 0.44 \%$ of inhibition of DPPH radical at $50 \mu \mathrm{M}$ respectively while in treated Anabaena sp. was at $10 \mu \mathrm{M}$ with $96.42 \pm 0.46 \%$ of inhibition of $\mathrm{DPPH}$ radical respectively.

Last but not least, radical scavenging activities in all $\mathrm{Cu}^{2+}$ treated cultures (Figure 4C) showed an increase compared to non-treated cultures at each time point and the most activity was at $D_{6}$ for all species. The highest antioxidant activity for all three species was recorded at 2 ppm Cu${ }^{2+}$ treatment with $89.67 \pm 0.61,87.18 \pm 0.69,78.68$ $\pm 0.62 \%$ of inhibition for $N$. oculata, Tetraselmis sp. and Anabaena sp. respectively.

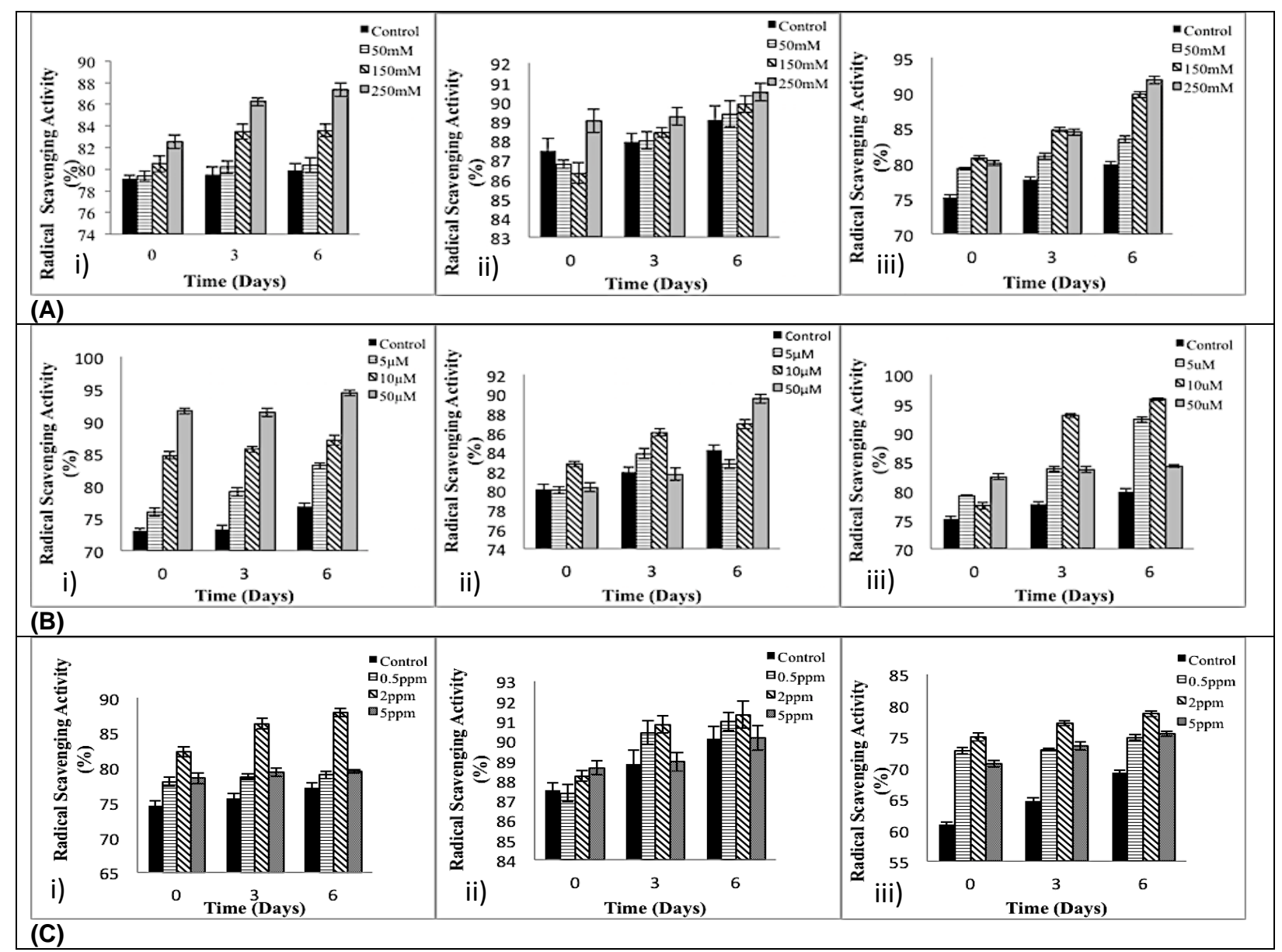

Figure 4: Radical scavenging activity before and after treatment of $(\mathrm{A}) \mathrm{NaCl},(\mathrm{B}) \mathrm{NaOCl}$ and $(\mathrm{C}) \mathrm{Cu}^{2+}$ in i) $\mathrm{N}$. oculata ii) Tetraselmis sp. iii) Anabaena sp. at different time points. All samples and control concentrations were $100 \mu \mathrm{g} / \mathrm{mL}$. Control is DPPH in methanol only. Radical scavenging activity was calculated after subtracting absorbance of samples from that of control. Each value in the graph is represented as mean $\pm \operatorname{SD}(n=3)$. 


\section{DISCUSSION}

This project was carried out in order to determine the amount of phenolic and flavonoid compounds as well as antioxidant activities in microalgae ( $N$. oculata and Tetraselmis sp.) and cyanobacterium (Anabaena sp.) under normal and under abiotic stress conditions. Cultures were treated with various concentrations of $\mathrm{NaCl}$ (salinity/ osmotic stress), copper ion $\left(\mathrm{Cu}^{2+}\right)$ and $\mathrm{NaOCl}$ (oxidative stress). Results from this study have shown to be in agreement with a study reported by Hasegawa et al. (2000) where antioxidant compounds were found to be associated as an adaptability strategy against stress conditions.

According to $\mathrm{Gu}$ et al. (2012) N. oculata growth was increased when treated with $\mathrm{NaCl}$ during 19 days of cultivation. Srivastava et al. (2005) stated that Anabaena sp. growth treated with $150 \mathrm{mM} \mathrm{NaCl}$ grew faster than control. In contrast, growth of treated Tetraselmis sp. was decreased over time for each treatment. Kirst (1990) explained that microalgae might lose dry biomass productivity or reduction in growth because they will expend energy while attempting to maintain turgor pressure under high salinity. Under oxidative stress, Galindo et al. (2010) reported that $\mathrm{NaOCl}$ have caused growth of microalgae Dunaliella salina to be inhibited after $24 \mathrm{~h}$. This previous work correlates with the growth of $\mathrm{NaOCl}$ treated Tetraselmis sp. in this study. Apart from that, growth of green microalgae was shown to be inhibited due to $\mathrm{Cu}^{2+}$ accumulation and toxicity by Anurag et al. (2014) but growth of treated $N$. oculata and Anabaena sp. in this study did not show the same trend. This might be due to the adaption of the organisms to $\mathrm{Cu}^{2+}$ stress.

In this study, N. oculata, Tetraselmis sp. and Anabaena sp. were extracted using $100 \%$ methanol as it was reported as the most efficient solvent for phenolic extraction and radical scavenging compounds in microalgae (Abd El-Aty et al., 2014). Total phenolic content was determined using Folin-Ciocalteu reagent to measure the total concentration of phenolic hydroxyl groups. Polyphenols react with sodium carbonate form a blue complex that can be read by visible-light spectrophotometry at $650 \mathrm{~nm}$ (Slinkard and Singleton 1977). This study explored total phenolic content in microalgae and cyanobacterium culture when treated with three different stresses. The first stress was $\mathrm{NaCl}$ to mimic salinity stress. $N$. oculata and Tetraselmis sp. and Anabaena sp. can be found both in fresh and marine water system. When water level drops, salinity will increase thus will cause the microalgae and cyanobacterium to experience stress. Total phenolic content in $\mathrm{NaCl}$ treated microalgae and cyanobacterium was increased proportionally with time and all were higher consistently than control. Kawasaki et al. (2001) and Ozturk et al. (2002) reported that salinity stress can cause a series of changes in photorespiration, photosynthesis, osmotic adjustment, amino acid and carbohydrate synthesis. Previous studies have also proven that phenolic compounds accumulate under salt stress conditions followed by enhanced antioxidative activity in Plectonema boryanum, Hapalosiphon intricatus, Anabaena doliolum and Oscillatoria acuta (Singh et al., 2014). Biosynthesis of phenolic compounds come from carbohydrate metabolism before they enter shikimate pathway and form phenylalanine and phenolic acid. The increase in carbohydrate content will increase total phenolic content. This was proved by Kirrolia et al. (2011) that reported carbohydrate content in microalgae Scenedesmus quadricauda was increased in all $\mathrm{NaCl}$ treatment as compared to control. Singh et al. (2014) also reported that salt stress induces the accumulation of phenylpropanoid and antioxidant activity in cyanobacteria and microalgae. However total phenolic content in treated Anabaena sp. showed no significant difference. This study showed that phenolic contents in $\mathrm{NaOCl}$ treated cultures were increased. Research done by Markou et al. (2012) showed decrease in phenol concentration and turbidity in A. platensis after $\mathrm{NaOCl}$ treatment. This might be due to concentration of $\mathrm{NaOCl}(5 \mu \mathrm{M}, 10 \mu \mathrm{M}$ and $50 \mu \mathrm{M})$ used in this treatment was not enough to cause any decrease in phenolic content and turbidity. However, according to Ip and Chen (2005) Chlorella zofingiensis treated with $0.0001 \mathrm{mM}$ of $\mathrm{NaOCl}$ gave high chlorophyll and carotenoid content.

Flavonoid content was determined using calorimetric method. Aluminium chloride forms acid stable complexes with the C-4 keto groups and either hydroxyl group of flavones and flavonols, orthodihydroxyl groups in the A- or B-ring of flavonoids which can be detected at wavelength $510 \mathrm{~nm}$ (Kalita et al., 2013). This research showed that total flavonoid content in treated cultures is higher than control at each time point. It is because flavonoids are the largest group of naturally occurring phenolic compounds such as flavonols, flavones, anthocyanidins, flavons and flavonols (Ohshima et al., 1998). N. oculata contains higher concentration of flavonoids compared to Tetraselmis sp. and Anabaena sp. Previous study by Barreiro et al. (2016) stated that accumulation of polyphenol was higher than control under copper stress in Dunaliella tertiolecta.

There are numerous methods used to evaluate antioxidant activity of natural compounds with varying results. 2,2-diphenyl-1-picrylhydrazyl (DPPH) is a free radical that is usually used to measure antioxidant activity. $\mathrm{DPPH}$ is reduced by antioxidant and can be measured at $510 \mathrm{~nm}$ (Abd El-Aty et al., 2014). Discoloration of DPPH showed that free radical scavenging potentials of the sample by their hydrogen donating ability (Pallab et al., 2013). When DPPH reacts with an antioxidant compound, which can donate hydrogen, it is reduced (Kalita et al., 2013). Goiris et al. (2012) reported that both carotenoid and phenolic content significantly contributed to the antioxidant capacity of microalgae. However, according to Hajimahmoodi et al. (2009), there was a positive correlation between antioxidant capacity and phenolic content only in FRAP (Ferric Reducing Antioxidant Potential) assay and not in 2,2-diphenyl-1-picrylhydrazyl High performance liquid chromatography (DPPH-HPLC). Maadane et al. (2015) stated that phenolic and 
carotenoids compounds might not be the major contributors to the antioxidant capacities of these microalgae. Winter et al. (2008) reported that $\mathrm{NaOCl}$ will form hypochlorous acid $(\mathrm{HOCl})$ when reacted with water which will interrupt protein folding and inhibit glucose oxidation thus cause biochemical damages to exposed organisms. The biocidal effect of $\mathrm{NaOCl}$ involves the action of free radicals generated which lead to oxidative stress (Leichert et al., 2008) and lipid peroxidation (Ebenezer and $\mathrm{Ki} 2014$ ). Thus, $\mathrm{NaOCl}$ is suitable as oxidative stress inducer to generate ROS by increasing the percentage of radical scavenging activity in all treated cultures. Manivannan et al. (2012) stated that antioxidant activity of methanolic extract in the presence of copper is higher than control. Srivastava et al. (2005) hypothesized that anti-oxidative defence system is stimulated in $A$. doliolum by copper. This study has showed that total phenolic and flavonoid contents in treated cultures were increased compared to non-treated cultures. This proved that abiotic stress induces the accumulation of phenolic and flavonoid contents thus increases free radical scavenging activity in microalgae and cyanobacterium.

Percentage of increase in $N$. oculata that showed highest total phenolic content under treatment with $\mathrm{NaCl}$ was $226 \%$ (8.64 $\pm 0.6 \mu \mathrm{g} \mathrm{GAE} / \mathrm{mg}$ extract). Percentage of increase in the highest total flavonoid content under $\mathrm{NaCl}$, $\mathrm{NaOCl}$ and $\mathrm{Cu}^{2+}$ stresses were 78, 32 and39\% (28.67 \pm 2, $31.4 \pm 0.56$ and $33.85 \pm 3.16 \mu \mathrm{g}$ QE/mg extract) respectively. Percentage of increase in Tetraselmis sp. that exhibit high phenolic content under $\mathrm{NaCl}$ and $\mathrm{Cu}^{2+}$ stresses were $15 \%$ and $48 \%(7.02 \pm 0.39,10.35 \pm 0.33 \mu \mathrm{g}$ $\mathrm{GAE} / \mathrm{mg}$ extract) respectively. Percentage of increase in Tetraselmis $\mathrm{sp}$. that exhibit high percentage of radical scavenging activity under $\mathrm{Cu}^{2+}$ treatment was $7 Z \%(91.31$ $\pm 0.69 \%$ ). Percentage of increase in Anabaena sp. that gave high percentage of radical scavenging activity under $\mathrm{NaCl}$ and $\mathrm{NaOCl}$ stresses were 12 and 16\% (91.8 \pm 0.52 and $96.42 \pm 0.26 \%$ ).

\section{CONCLUSION}

As a conclusion, high phenolic and flavonoid content and increased percentage of free radical scavenging activities were observed after induction of stress in local microalgae and cyanobacterium. Tetraselmis sp. and Anabaena sp. showed that they have the potential to be developed as a natural source of these useful compounds. However, further studies should be carried out to identify and quantify these bioactive compounds alongside looking at the best stress inducer for further studies. It is hoped that this study will contribute to the search for a natural source of useful bioactive compounds.

\section{ACKNOWLEDGEMENT}

This work was carried out with the support of "Geran Putra Universiti Putra Malaysia (Project No.: 9425900)", Universiti Putra Malaysia, Serdang, Selangor, Malaysia.

\section{REFERENCES}

Abd El-Aty, A. Mohamed, A. A. and Samhan, F. (2014). In vitro antioxidant and antibacterial activities of two fresh water cyanobacterial species, Oscillatoria agardhii and Anabaena sphaerica. Journal Application Pharmcy Science 4, 69-75.

Anurag, T. and Bafila, G. (2014). Copper stress on cellular contents and fatty acid profiles in Chlorella species. Journal of Biological Sciences 14, 209-217.

Barreiro, D., Prins, W. and Ronsse, F. (2016). Hydrothermal liquefaction (HTL) of microalgae for biofuel production. Journal of Biomass and Bioenergy 53,113-127.

Blois, M. S. (1958). Antioxidant determinations by the use of a stable free radical. Nature 26, 1199-1200.

Ebenezer, V. and Ki, J. (2014). Biocide sodium hypochlorite decreases pigment production and induces oxidative damage in the harmful dinoflagellate cochlodinium polykrikoides. Journal of Algae 29, 311319.

Galindo, C., Garrido, M. C., Casanueva, J. F. and Nebot, E. (2010). Degradation models and ecotoxicity in marine waters of two antifouling compounds: Sodium hypochlorite and an alkylamine surfactant. Science of the Total Environment 408, 1779-1785.

Goiris, K., Muylaert, K., Fraeye, I., Foubert, I., De Brabanter, J. and De Cooman, L. (2012). Antioxidant potential of microalgae in relation to their phenolic and carotenoid content. Journal Application Phycology 24, 1477-1486.

Gu, N., Lin, Q., Li, G., Tan, Y., Huang, L. and Lin, J. (2012). Effect of salinity on growth, biochemical composition and lipid productivity of Nannochloropsis oculata CS 179. Engineering in Life Sciences 12, 631637.

Guedes, A. C., Amaro, H. M., Pereira, R. D. and Malcata, F. X. (2011). Effects of temperature and $\mathrm{pH}$ on growth and antioxidant content of the microalga Scenedesmus obliquus. Biotechnology Progress 27, 1218-1224.

Hajimahmoodi, M., Faramarzi, M. A., Mohammadi, N., Soltani, N., Oveisi, M. R. and Nafissi Varcheh, N. (2009). Evaluation of antioxidant properties and total phenolic contents of some strains of microalgae. Journal Application Phycology 22, 43-50.

Hasegawa, P. M., Bressan, R. A., Zhu, J. K. and Bohnert, H. J. (2000). Plant cellular and molecular response to high salinity. Plant Molecular Biology 51, 463- 499.

Ip, P. and Chen, F (2005). Employment of reactive oxygen species to enhance astaxanthin formation in Chlorella zofingiensis in heterotrophic culture. Journal of Process Biochemistry 40, 3491-3496.

Kalita, P., Barman, T. K., Tapas, P. K. and Ramen, K. (2013). Estimation of total flavonoids content (tfc) and antioxidant activities of methanolic whole plant extract of biophytum sensitivum linn. Journal of Drug Delivery and Therapeutics 3, 33-37. 
Kawasaki, S., Borchert, C., Deyholos, M., Wang, H., Brazille, S., Kawai, K., Galbraith, D. and Bohnert, H. J. (2001). Gene expression profiles during the initial phase of salt stress in rice. Journal of Plant Cell 13, 889-905.

Kirrolia, A., Bishnoi, N. and Singh, N. (2011). Salinity as a factor affecting the physiological and biochemical traits of Scenedesmus quadricauda. Journal of Algal Biomass Utilization 2, 28-34.

Kirst, G. O. (1990). Salinity tolerance of eukaryotic marine algae. Annual Review of Plant Physiology and Plant Molecular Biology 41, 21-53.

Klejdus, B., Lojkova, L., Plaza, M., Šnoblova, M. and Štěrbova, D. (2010). Hyphenated technique for the extraction and determination of isoflavones in algae: Ultrasoundassisted supercritical fluid extraction followed by fast chromatography with tandem mass spectrometry. Journal of Chromatography 1217, 79567965.

Kováčik, J., Klejdus, B., Bačkor, M. (2010). Physiological Responses of Scenedesmus quadricauda (Chlorophyceae) to UV-A and UV-C Light. Photochemistry and Photobiology 86, 612-616.

Kreslavski, V. D., Carpentier, R., Klimov, V. V., Murata, N. and Allakhverdiev, S. I. (2007). Molecular mechanisms of stress resistance of the photosynthetic apparatus. Membrane and Cell Biology 1, 185-205.

Leichert, L. I., Gehrke, F., Gudiseva, H. V., Blackwell, T., Ilbert, M., Walker, A. K., Strahler, J. R., Andrews, P. C., and Jakob, U. (2008). Quantifying changes in the thiol redox proteome upon oxidative stress in vivo. Proceedings of the National Academy of Sciences USA 105, 8197-8202.

Maadane, A., Merghoub, N., Ainane, T., Arroussi, H. E., Benhima, R. Amzazi, S. and Wahby, I. (2015). Antioxidant activity of some Moroccan marine microalgae: Pufa profiles, carotenoids and phenolic content. Journal of Biotechnology 21, 13-19.

Manivannan, K., Ananthraman, P. and Balasubramanian, T. (2012). Evaluation of antioxidant properties of marine microalga Chlorella marina. Asian Pacific Journal Tropical Biomedical 2, 42-46.

Markou, G., Chatzipavlidisb, I. and Georgakakis, D. (2012). Cultivation of Arthrospira (Spirulina) platensis in olive-oil mill wastewater treated with sodium hypochlorite. Bioresource Tecnology 11, 234-241.

Natrah, F. M., Yusoff, F. M., Shariff, M., Abas, F. and Mariana, N. S. (2007). Screening of Malaysian indigenous microalgae for antioxidant properties and nutritional value. Journal of Applied Phycology 19, 711-718.

Ohshima, H., Yoshie, Y., Auriol, S. and Gilibert, I. (1998). Antioxidant and pro-oxidant actions of flavonoids: Effects on DNA damage induced by nitric oxide, peroxynitrite and nitroxyl anion. Free Radical Biology and Medicine 25, 1057-1065.

Ozturk, Z. N., Talame, V., Deyholos, M., Michalowski, C. B., Galbraith, D. W., Gozukirmizi, N. and Bohnert, H. J. (2002). Monitoring large-scale changes in transcript abundance in drought and salt stressed barley. Plant Molecular Biology 48, 551-573.

Pallab, K. T., Barma, K., Pal Tapas, K. and Ramen (2013). Research article estimation of total flavonoids content (TFC) and anti-oxidant activities of methanolic whole plant extract of Biophytum. Journal of Drug Delivery and Therapeutics 3: 33-37.

Singh, D., Prabha, R. and Meena, K. (2014). Induced accumulation of polyphenolics and flavonoids in cyanobacteria under salt stress protects organisms through enhanced antioxidant activity. American Journal of Plant Sciences 5, 726-735.

Slinkard, K. and Singleton, V. L. (1977). Total phenol analyses: Automation and comparison with manual methods. American Journal of Enology and Viticulture 28, 49-55.

Srivastava, A. K., Bhargava, P. and Rai, L. C. (2005). Salinity and copper-induced oxidative damage and changes in the antioxidative defence systems of Anabaena doliolum. World Journal of Microbiology and Biotechnology 21, 1291-1298.

Winter, J., Ilbert, M., Graf, P. C. F., Özcelik, D. and Jakob, U. (2008). Bleach activates a redox-regulated chaperone by oxidative protein unfolding. Cell 135, 691-701.

Zhishen, J., Mengcheng, T. and Jianming, W. (1999). The determination of flavonoid contents in mulberry and their scavenging effects on superoxide radicals. Food Chemistry 64, 555-559. 